\title{
Sexos em guerra
}

\section{Hommes et femmes dans la France en guerre (1914-1945).}

CAPDEVILA, LUC; ROUQ UET, François; VIRG ILI, Fabrice; VOLMAN, Da nièle.

Paris: Payot e Rivages, 2003. 362 p.

Agosto de 1914: em duas semanas, 3,6 milhões de homens foram convocados para a guerra; setembro de 1939: em dez dias, 5 milhões de homens integraram o dispositivo militar. 0 recrutamento, em uma tal amplitude, de uma parcela da população francesa - a masculina não ocorreu sem provocar enormes transformações na sociedade, da célula mais básica, a família, à organização produtiva do país. Essas mudanças tiveram como conseqüência uma revisão considerável dos papéis socia is das mulheres e dos homens. Partindo dessa tese, Luc Capdevila, François
Rouquet, Fabrice Virgili e Danièle Voldman percorrem os diversos lugares reservados aos homens e às mulheres na sociedade francesa, bem como as representações estereotipa das dos dois sexos, apontando as transformações que foram ocorrendo em função das necessidades cria daspelo esforço de guema. Tempos de guerra são momentos privilegiados para se discutir as identidades de gênero, pois, como os autores mostram bem, a questão homem-mulher sai da esfera privada para adentrar no cenário político. Além disso, há uma mudança de eixo na socieda de, desorganizando a vida civil e trazendo situações excepciona is, em que as fronteira sentre os gêneros se confundem e, em certas situações, chegam a se inverter.

Fruto de vários a nos de pesquisas, estudos e seminários, Hommes et femmes dans la France em guerre (1914-1945) foi escrito a oito mãos, em um processo bastante complexo de escrita individual, leitura coletiva, crítica, revisão e reescrita. O resultado é bastante profícuo, na medida em que fomece uma visão multifac eta da dos assuntos abordados. A grande inovação do 
livro está em tratar o gênero como categoria histórica, ou seja, como uma construção social evolutiva, que se modifica com o passar do tempo. Outra novidade foi tratar o tema em paralelo nas duasguerras, integrando a dimensão masculina. Masculino e feminino são abordados de forma ind issociá vel, enqua nto sistema. Assim, embora a questão da disputa de poder seja um elemento bastante importante na constituição da categoria de gênero, os autores vão a lém disso, identificando, a cada momento, as diversas composições possíveis, e muitas vezes contraditórias, dos papéis socia is a tribuídos a homens e mulheres.

Os a uto res sã o todos liga dos a o Instituto de História do Tempo Presente e não são considerados, pelo menos na França, especialistas em história do gênero. São pesquisa dores da guema que resolveram integrar a discussão do gênero em seus estudos. Nesse sentido, é c urioso notar que, dos qua tro, três são homens, uma proporção rara de encontrar em trabalhos desse tipo - em que a representação feminina ainda é majoritária.

Nesse estudo, história cultural e história social não se distinguem. A política do Estado, a sexualidade doscidadã os franceses, a violência da guerra, o cotidiano no front, a vida civil, sã o questões que, por sua complexidade e interligações, não podem ser reduzidas a um ou outro aspecto. As fontes também são variadas: relatórios de polícia, jornais, projetos de lei, documentos militares, correspondências de guerra, discursos oficiais, relatos de excombatentes, textos literá rios - estesúltimos sendo empregados predominantemente para ilustrar determina das situações. A bibliog rafia reunida é extensa e data, em grande parte, dos a nos 1990 para cá, o que demonstra o quanto a problemática é recente.

O livro inicia-se com um capítulo teórico, em que se discutem a evolução do conceito de identidade e suas relações com a categoria de gênero, assim como a trajetória do estudo das duas guerras mundia is. Seria interessante, a título introdutório, explicitar melhor as principa is diferenças entre a Primeira e a Segunda Guerras Mundiais. Embora haja uma certa preocupação em deixar sempre clara a enorme diferença de contexto e de sociedade entre as duas guerras, nem sempre se consegue demarcá-las devidamente. Por exemplo: os dados sobre os mortos em cada guerra não são seguidos do total da população nos peńod os correspondentes, de maneira que a comparação entre as duas - em termos gerais - fica prejudicada. Além disso, temos de esperar até a página 182 para sabermos que a Primeira Guerra foi uma guerra de posições, que se restring iu a os departa mentos do norte e do leste, entre dois inimigos cla ramente identificados, enquanto na Segunda Guerra a situa ção era ma is complexa: o comba te clássico foi combinado à guerrilha, houve um número muito maior de combates aéreos e de bombardeamentos - a ting indo a população civil -, sem falar das diversas formas de repressão postas em prática pelo ocupante, como a deportação e a tortura.

Em a mbos os conflitos, as autoridades francesas mobilizaram homens e mulheres no esforço de guerra: a legislação, os discursos oficiais, a propaganda indicavam o lugar que cabia a cada sexo na cruzada bélica. Homens lutando no front, mulheresem casa, cuidando dos filhos e garantindo o bom funcionamento da socieda de civil. Esses lugares, no enta nto, não são estanques e vão sendo altera dos de a cordo com as necessidades: homens antes destinados ao combate podiam serconvocados para trabalhar na indústria - bélica, principalmente - e mulheres podiam acercar-se dos campos de batalha cuidando dos feridos, como enfermeiras, ou substituir os homens na agricultura e na indústria, a fim de garantir a produtividade da nação.

Houve, além disso, uma a propriação pelo Estado de uma questão privada, o sexo, para enquadrá-lo na esfera política, a tra vés de uma série de medidas visando ao controle da sexualidade da população. 0 reforço da moral e a repressão dos desvios tomaram-se parte integrante da estratégia de garantir o bom curso da guema. O reforço da família, a tra vés de ajudas financeiras e de incentivos à natalidade, era a companhado da censura ao divórcio, ao aborto, à infidelidade. Além disso, houve uma grande preocupação no que diz respeito à prostituição e aos riscos que dela decomiam devassidão moral e doenças venérias - ao mesmo tempo que era considerada um mal nec essá rio para a liviar as tensões dos solda dos.

Por outro lado, a realidade da guerra pôs em xeque as fronteiras das identidades sexua is. Em situações-limite - quando a população civil se encontrava sob o perigo das bombas, ou nos grandes deslocamentos de uma região a outra (em maio-junho de 1940, de 6 a 8 milhões de pessoas a travessaram o país, deslocando-se do norte em direção a o sul) -, muita s vezes os pa péis socia is a tribuídos a um ou outro sexo deixavam de tersentido e cediam espaço para as inic iativas individuais. Determinadas experiências representam um golpe pesado nas imagens de 
gênero. A virilida de dos homens que poralguma razão abandonavam o campo de batalha, ou dos que integravam a categoria de feridos de guerra - incapazes de voltar à 'vida normal' -, era imediatamente colocada em xeque. Do mesmo modo, as mulheres que se viram responsáveis pelo sustento dos filhos, ou que decidiram partirpara o combate nas trincheiras, estavam fora do padrão corrente de feminilidade.

Em a lgumas situações, chegou a haveruma completa inversão dos papéis, opondo, por exemplo, homens que não conseguiram reintegra r-se socialmente, devido a seus traumas de guerra, e mulheresque passaram a participar do mercado de trabalho. Um bom exemplo dessas situações, em que os pa péis socia is entram em conflito, é o que ocorreu em Arras, em 1915. Durante um bombardeamento, uma enfermeira recusou-se a ir para o abrigo e abandonar os doentes não transportáveis, a despeito de todos os argumentos de seus colegas. Em suas memórias, ela menciona o drama de ter de escolher entre seus deveres matema is e sua consciência profissional. Só se decidiu quando o médico, colocando-se diante dela em uma posição de igualdade, a rgumentou que ambos tinham filhos e precisava $m$ proteger-se, pois nã o podiam fazer mais nada pelos outros doentes naquela situação.

Concretamente, o que foi de fato modificado nesse jogo de vai-e-vem, entre a demarcação reforçada das fronteiras sexua is de um lado - pelos discursos políticos, pelo acirramento do controle estatal sobre a sexualidade da população - e seu enfraquecimento pela realidade da guerra homens fragilizados, mulheres assumindo novas funções - por outro? Em que sentido as guerras foram um fator determinante nessas mudanças? A conclusão encontra-se mais no primeiro capítulo do que no último. Segundo os autores, houve uma transformação das relações entre homens e mulheres em dois níveis: em um movimento lateral, que teria aproximado os papéis reservados a homens e mulheres durante a guerra e, em outro sentido, em um movimento vertical, atenuando a hierarquia entre os dois sexos. A idéia é interessante, masum pouco vaga. Provavelmente essa sensação de falta de nitidez deve-se a o fa to de o livro ser um painel bastante fragmentado - os temas são correlatos, mas dispersos - e principalmente de se passar com excessiva facilidade da guerra de 1914-1918 à de 1939-1945.

No entanto, a lgumas pistas sã o da das pelos autores. Da Primeira Guerra para a Segunda, a imagem das enfermeiras banalizou-se e cedeu espaço para a da mulher que integrava a Resistência. A heroína deslocou-se daquela que cura para aquela que combate. Paralelamente, as mulheres passaram a desempenhar funções até então reservadas aos homens, ocupando diversos setores da atividade produtiva, seja no campo, seja na cidade. Evidentemente esse processo não é linear e tem seus entraves. As mulheres sempre rec eberam salários inferiores a os dos homense houve uma tendência à distribuição de papéis dentro do mercado de trabalho, com uma definição de qualidades profissionais eminentemente femininas e outras masculinas.

Talvez a situação que melhor ilustre a complexidade das transformações seja a que ocorreu em agosto de 1944, quando um desta camento do Como feminino de transmissões desembarcou na Provença. A maiorparte dessas mulheres já havia participado da campanha da Itália, mas, nem naquela ocasião nem na presente, havia $m$ recebido a mas para combater. Como haviam chegado mais rapidamente no terreno do que se previa, seu alojamento a inda não havia sido providenciado. Então, ofereceramIhes uma granja para que passassem lá a primeira noite. Pela primeira e única vezna guerra, deramIhes algumas granadas, para que pudessem se defender de um ataque qualquer, fosse ele do inimigo, fosse do exército aliado. Assim, em três anos, apesar de terem participado de várias campanhas - na Itália, na França e, depois, na Alemanha -, essas mulheres foram armadas apenasuma vez, não para proteger-se do inimigo, mas... dos homens. Por um lado, elas ocupavam o espaço máximo da virilidade, o campo de batalha; por outro, eram alvo fácil ao mesmo tempo do inimigo da nação e do sexo oposto.

Apesar da falta de uma amarração mais articulada dos diversos elementos apresentados no decorrer do livro, Hommes et femmes dans la France em guerre (1914-1945) é um estudo extremamente interessante. Ao abordaros diversos aspectos envolvidos na relação entre homens e mulheres em situação de guerra, perscruta questões inesperadas que se encontram no cruzamento entre a maneira como a identidade de gênero é percebida pelos indivíduos, a política do Estado em determinadas circunstâncias visando a resultados específic os - e as situações caóticas e dramáticas provocadas pelo deslocamento de grande parte dos esforços da nação no sentido de um confronto bélic 0 .

Ma riana J offily Universidade de São Paulo 